http://dx.doi.org/10.4314/ejotmas.v7i1-2.2

\title{
ONLINE SELF-DISCLOSURE AMONG STUDENTS OF HIGHER INSTITUTIONS OF LEARNING IN IBADAN METROPOLIS, NIGERIA
}

\author{
*Olayinka Abimbola EGBOKHARE, Ph.D. \\ **Adeola Obafemi MOBOLAJI
}

\begin{abstract}
The popularity of social network sites has influenced communication behaviour in a variety of contexts. Thus, this study examined the online behaviour of social media users as regards self-disclosure, motivations and gratifications. The study adopted Social Penetration Theory by Irwin Altman and Dalmas Taylor and data were gathered through questionnaire from randomly selected 330 respondents and from purposively selected 16 respondents in two sessions of Focus Group Discussion (FGD) among the students of University of Ibadan and the Polytechnic Ibadan. Although some respondents agreed that relationship management (56.1\%) and need for self-expression (60.3\%) motivated them to self-disclose on Facebook and Instagram, most disagreed that reciprocity (65.0\%), mutual self-disclosure (78.2\%), social validation (66.3\%) and show off (78.6\%) motivated them. Also, most respondents agreed that they sought gratifications from intimate relationship (56.1\%), killing boredom (55.4\%), seeking people's opinions (67.3\%) and maintaining online conversation (58.0\%). However, qualitative data revealed that most respondents were motivated by and also sought gratifications from many of the factors aforementioned for online self-disclosure. Therefore, this study recommended that social media users should be orientated on the proper use of social media as it is obvious that many of them lack the requisite online literacy knowledge; with this, social media users will make use of the platform without risking their privacy.
\end{abstract}

Keywords: Online self-disclosure, Facebook, Instagram, SPT, Social media users

\footnotetext{
*Olayinka Abimbola EGBOKHARE, Ph.D. is of the Department of Communication and Language Arts, University of Ibadan, Ibadan, Nigeria Email:yinkaegbokhare@yahoo.com

**Adeola Obafemi MOBOLAJI is of the Department of Communication and Language Arts, University of Ibadan, Ibadan, Nigeria Email:adeolamobolaji@gmail.com
} 


\section{Introduction}

Social media has changed the communication landscape and the way people communicate. It has provided opportunities for people to engage in quick online interactions in situations where face-to-face interaction is not possible, especially due to distance and location. The present age is an era of information and communication revolution. The advent of social network sites such as Instagram, Facebook, Twitter, Badoo, BBM, Whatsapp, LinkedIn, and YouTube has made it possible for information to be easily passed around the globe and to network with people without necessarily meeting them in person (Omoera et al., 2018). The foregoing submission is consistent with the position of Eke, Omekwu and Odoh (2014) that social networking sites such as Facebook, Twitter, MySpace, and Skype have mesmerized millions of users many of who have made the sites part of their daily activities.

According to Baruah (2012), the term social media refers to the use of web-based and mobile technologies to turn communication into an interactive dialogue. He adds that social media is media for social interaction as a superset beyond social communication. Enabled by ubiquitously accessible and scalable communication techniques, social media has substantially changed the way organizations, communities, and individuals communicate. This means that social media, with the help of technology, has redefined social communication by enabling easy interaction among people in different facets of life. However, it is important to note that the use of social media involves sharing and disclosing of personal details. It could be said that self-disclosure of the details of social media users is one of the reasons why its use seems to be more appealing compared to other media of communication. This view is confirmed by Baruah (2012) that, one of the most important advantages of social media is the online sharing of knowledge and information among different groups of people.

Therefore, as people disclose and share information on social media, their privacy is being affected. In view of this, Yat (2012) claims that the privacy problem about disclosure of personal information on social network becomes the hottest issue that arouses much public concern and discussion. He adds that along with the increasing social network user base, this problem cannot be ignored because social network contains plenty of personal information which may bring about commercial interest and illegal usage of the information. Also, in the study, "Teens, Social Media and Privacy" by Madden et al. (2013), it is revealed that youths are sharing more personal information on their profiles than in the past. They choose private settings for Facebook, but share with large networks of friends. The findings of the study also show that most teen social media users are not very concerned 
about third-party access to their data.Bazarova and Choi (2014) used functional approach in connecting self-disclosure goals to message characteristics that requires looking into actual communication content and goals associated with it. Their findings reveal that self-disclosures in Facebook status updates, wall posts, and private messaging are motivated by different reward values. Based on their findings, they suggest that one way to consider differences between self-disclosure goals is by mapping them onto intrapersonal-interpersonal orientation, which represents the extent of orientation toward the self or the other and the level of interdependency between the discloser and receiver.

Furthermore, some questions still need to be answered; such as, is there any connection between privacy awareness and selfdisclosure decision on social media? Do social media users seek gratifications of online self-disclosure more than online privacy management? Thus, this study seeks to know the factors that motivate social media users to disclose their private information online. It will also explore the gratifications that social media users derive in disclosing their personal information online. In addition, in the scholars' work reviewed, there appears to be a dearth of systematic and empirical investigation in Africa and Nigeria in particular, on online self-disclosure and its motivating factors on social network sites by students of higher institutions of learning. It is based on this noticeable gap that this article investigates the factors responsible for self-disclosure of students from the University of Ibadan and Polytechnic Ibadan, and the gratifications students seek from self-disclosure as online media users.

\section{Self-disclosure}

Interaction has become flexible and easier through social network and this is only made possible through sharing of information with one another. Self-disclosure is a way by which people disclose their private information in order to maintain and sustain relationship in online and offline context. In the view of Rime (2016), self-disclosure is defined as "the act of making yourself manifest, showing yourself so others can perceive you". This portends that self-disclosure occurs when people try to make some information about them known to others in order to establish a virile relationship.

Masaviru (2016), in a broader context, claims that "self-disclosure is the act of revealing details about ourselves to others". He adds that the topics of disclosure range from superficial details to very private, sensitive and personal information. He, however, argues that any verbal or non-verbal communication that reveals something about the self is self-disclosure. The argument of Masaviru (2016) shows that self- 
disclosure is not only limited to verbal communication. Any non-verbal cue that reveals something about one to others is self-disclosure. In line with this, Rime (2016) emphasizes that self-disclosure is a process that plays a major role in the development, maintenance and enhancement of close relationships. This supports the fact that selfdisclosure is for relationship building. From another point of view, Ledbetter et al. (2010) note that social competence of people can define their pattern of disclosure. They state that in online relationships, lack of social competence may account for heightened self-disclosure online because those with poor social skills may prefer the greater control over communication behaviour that online contexts afford. They explained further that:

Those individuals that have the social skills needed to communicate themselves well and effectively, have little need to express their true selves or "Real Me" over the Internet. The rest of us should be glad that the Internet exists. Thus we would expect people who are lonely or are socially anxious in traditional, face to- face interaction settings to be likely to feel better able to express their true self over the Internet and so to develop close and meaningful relationships there. (Ledbetter et al., 2010)

The quote explains that people that do not communicate very well in the face-to-face interaction may easily express themselves to people online in order to develop a meaningful relationship and to find a solution to their weak communication in the natural world. On the other hand, people with better social skills to relate and communicate with people in the real world may have a low level of self-disclosure in an online platform. In addition to the above point about online self-disclosure, it should also be noted that self-disclosed information on the Internet differs since it is digital, which makes the information to be persistent, replicable, scalable, searchable and shareable (Ghamari \& Mellbin, 2015). Nevertheless, it is important to know that self-disclosure has both advantages and disadvantages. In relation to its merit, it allows people to open up and disclose more with people who disclose too (Steinberg, 2007). Second, it is a reciprocal process where the more one discloses to others, the more they will be willing to reciprocate (Steinberg, 2007). Third, disclosure leads to trust that develops the relationship. However, talking too much about ourselves early in a relationship may not facilitate the development of friendship because too much disclosure might be viewed as being 
insecure. As a result, Steinberg concludes that self-disclosure can lead to rejection in a situation where someone who discloses information is not being liked or accepted (2007). Therefore, selfdisclosure is subject to various issues and factors. Some of these factors are cultural differences, individual traits, differences in interpersonal skills and gender.

Table 1: The Model of Self-Disclosure

The Johari Window Pane

\begin{tabular}{|l|c|}
\hline OPEN PANE & BLIND PANE \\
\hline HIDDEN PANE & UNKNOWN PANE \\
\hline
\end{tabular}

Masaviru (2016)

Johari Window is a model for self-disclosure and it has four panes. All the four panes explain how information is disclosed among communication partners. Open pane has to do with the public area and this allows us to disclose any information willingly and freely. Information such as name, job, club and other superficial details about us are revealed here. In addition, most people will know some of your interests and family information. In the explanation of Masaviru (2016), the knowledge that the window represents, can include not only factual information, but feelings, motives, behaviours, wants, needs and desires, etc., indeed, any information describing who you are. It also important to note that on a first meeting with a new person, the size of the opening of this first quadrant is not very large, since there has been little time to exchange information (Chapman, 2003).

Hidden pane has information that people are not willing to let others know about. Information about sexual life, salary, past mistakes, failures, success, marital problems, and health issues belongs to the hidden pane. However, as people get to know each other better, the level of trust will increase and one will be more comfortable in disclosing personal information. Furthermore, blind pane has all the things that others know about one, but one is not aware. Unknown pane contains mysteries that are known to no one. It is the unexplored area (Steinberg, 2007). When the open quadrant is enlarged, more information is revealed and there comes self-disclosure. Simply put, Sprecher and Hendrick (2004) maintain that, as people share information about themselves, they move from the hidden area to the open pane. Therefore, the responsiveness and reciprocity of others will help in getting rid of the unknown pane. 


\section{Facebook}

Facebook was developed in 2004 by then Harvard University student Mark Zuckerberg. Facebook is a social networking site that is used by more than 800 million active users in every country on planet earth, so far in 70 languages and it is one of the most used social networking sites by university undergraduates. This fact is confirmed by the Debatin et al. (2009) that since its inception in 2004, this popular social network service has quickly become both a basic tool for and a mirror of social interaction, personal identity, and network building among students. In recent times, so many innovations have been added to Facebook. Now, Facebook has given its users opportunity to make and receive audio and video calls. Video can also be streamed live on Facebook for instant broadcast. These among other innovative features of Facebook are part of the reasons why students of higher institutions of learning make use of it.

It is important to note that Facebook has all the three attributes of social networking sites included in the definition of Boyd and Ellison (2008). In spite of the benefit that students are enjoying from Facebook, there are so many privacy issues affecting its users. In view of this, Debatin et al. (2009) while talking about the flaws of Facebook note that third parties can use Facebook for data mining, phishing, and other malicious purposes. Moreover, the findings of Harvey and Soltren (2005) reveal that Facebook was firmly entrenched in college students' lives, but users had not restricted who had access to this portion of their life. Their findings also reveal questionable information practices with Facebook, and found that third parties were actively seeking out information. This defenselessness of Facebook could be linked to the way the network is patterned. In view of this, Ahn (2011, p.1436) notes that "when a teenager joins a site like Facebook, they (sic) first create a personal profile. These profiles display information such as one's name, relationship status, occupation, photos, videos, religion, ethnicity, and personal interests". What Ahn says points to the fact: Facebook users inevitably self-disclose their private information because profile information that is provided by Facebook users is privacy sensitive.

\section{Instagram}

Instagram is a mobile, desktop and internet based photo-sharing application and service that allows users to share pictures and videos either publicly or privately. It was created by Kevin Systrom and Mike Krieger and launched in 2010 as a free mobile application exclusively for the IPhone operating system (IOS). Drawing from the history of Instagram by $\mathrm{Hu}$, Manikonda and Kambhampati (2014), Instagram, a mobile photo (and video) capturing and sharing service, has quickly 
emerged as a new medium in the recent years. It provides users an instantaneous way to capture and share their life moments with friends through a series of (filter manipulated) pictures and videos. Since its commencement, it has attracted more than 150 million active users, with an average of 55 million photos uploaded by users per day, and more than 16 billion photos shared so far (Instagram, 2013). It offers its users a unique way to post pictures and videos using their smartphones. Instagram applies different manipulation tools, 16 filters in order to transform the appearance of an image, and share them instantly on multiple platforms (e.g., Twitter and Facebook) in addition to the user's Instagram page.

Instagram also allows users to add captions, hashtags using the \# symbol to describe the pictures and videos, and tag or mention other users by using the @ symbol (which effectively creates a link from their posts to the referenced user's account) before posting them. It is evident that with the way Instagram works, it may be difficult for its users to maintain a reasonable level of privacy while using it and thus making self-disclosure inevitable. According to Ali-Al, Srinivas and Hammad (2016) in their study of the media uses and gratifications model to examine the needs and motives of Instagram users that predict self-disclosure; Instagram provides categories of needs and motives similar in nature to those of the other social networks, such as, selfexpression, entertainment and opinion exchange. They, however, note that Instagram caters for the need of experimenting with photography that few available social networks satisfy.

In the submission Ali-Al et al. (2016), self-expression and social interaction needs were the strongest predictors of the use of Instagram for self-disclosure. Corroborating this, Kusyanti and Safitiri (2016) claim that Instagram users publicize themselves through photos on Instagram. They add that the willingness of Instagram users to upload their photographs and other private information on Instagram is influenced by several factors. Some of these factors are trust in members, trust in provider, relationship building, enjoyment, convenience, and self-presentation and so on. They conclude that, the factors that influence individuals to publish themselves through photos uploaded on Instagram are the advantages that are derived from uploading photos on Instagram. Some of the advantages could be positive comments from other users and the number of "likes"; the more the "likes" Instagram users get on their photos and videos, the more they are willing to upload (Kusyanti and Safitiri, 2016). The implication of this is that, the gratification sought by the users of Instagram would have reduced the perceived privacy risks and privacy concerns that are attached to the upload of photos and videos and this will ultimately affect their beliefs about privacy on Instagram and 
thereby making them to disclose more, as long as they are being gratified.

\section{Social Penetration Theory}

Social Penetration is defined by West and Turner (2010) as a process of relationship bonding whereby individuals move from superficial communication to more intimate communication. This theory was developed by psychologists Irwin Altman and Dalmas Taylor in 1973. It states that relationship begins and deepens through self-disclosure. At the start, people establish relationships by disclosing many simple, harmless facts through normal conversation. Altman and Taylor (1973) note that as relationships grow, the rate of self-disclosure recedes, while the facts disclosed become increasingly intimate in nature. This means that at a stage in relationship, the rate at which sensitive information is disclosed becomes high. And at this stage, others are able to penetrate a person's public space and discover his or her innermost self.

For better understanding of the connection between relationship and self-disclosure, Altman and Taylor in Littlejohn and Foss (2009) identify series of stages through which relationship could be developed. The first stage is the orientation stage. This is the first stage in the development of any relationship. At this stage, people start with short, simple, and usually inconsequential talk. This is a stage where people get acquainted to one another and the process of interpersonal intimacy development begins (Yang \& Tan, 2012). At exploratoryaffective stage, individuals now start to reveal themselves, expressing personal attitudes about public topics such as government and education. This is the stage of casual friendship, and many relationships do not go beyond this stage. Furthermore, all actions at this stage are channeled at the development of a close relationship, which is the main essence of self-disclosure (Collins and Miller, 1994).

Furthermore, affective stage is the juncture where people start to talk about private and personal matters. Criticism and arguments may also arise. There may be intimate touching and hugging at this stage. At this stage, relationship becomes stronger and partners get to interact more. As more information is disclosed by partners, likeness grows and intimacy is built. Moreover, at the stable stage, the relationship now reaches a level where personal things are shared, and one can predict the emotional reactions of the other person. Before this stage could be achieved, there must have been a continuous interaction by people. At this stage, the relationship has grown to a level where intimacy has reached a higher level. Lastly, de-penetration sets in and this is when the relationship starts to break down and 
costs exceed benefits, there is a withdrawal of disclosure that leads to termination of the relationship.

\section{Methodological Consideration}

Quantitative and qualitative research designs were adopted for this study, while survey and focus group discussion were used as method of data gathering. Survey was suitable for this study because the researchers were able to elicit information concerning respondents' beliefs, behaviours, views and perceptions. Questionnaire and Focus Group Discussion guide (FGD guide) were also chosen to get the detailed knowledge, reasons and rationale behind each of the respondents' views and responses on the research question. Purposive sampling technique was used to select students with accessibility to social media tool, especially Facebook and Instagram from the University of Ibadan and Polytechnic Ibadan. In addition, the selected students were those that were active on a social network site, at least twice a week and who were willing to participate in the study. For questionnaire, the representative sample drawn from the population for this study was a total of 330 across the two selected higher institutions in Ibadan, that is, 165 respondents from each institution. Quota sampling was also used by the researchers to select a total of 8 participants each to participate in the two sessions of Focus Group Discussion (FGD). A total number of 330 copies of the questionnaire were administered to respondents by the researchers and some research assistants in the selected locations for the study. Out of this number, only 312 copies were retrieved. Data were analysed through frequency counts and simple percentage score with findings presented in tables while responses from the Focus Group Discussion were recorded, transcribed and extracted to support findings from the study. 


\section{Results and Discussion of Findings}

Table 2: Respondents' motivational factors for self-disclosure on Facebook and Instagram

\begin{tabular}{|l|c|c|c|c|c}
\hline $\begin{array}{l}\text { Motivational factors for self- } \\
\text { disclosure: }\end{array}$ & $\begin{array}{l}\text { Strongly } \\
\text { Agree }\end{array}$ & Agree & Disagree & $\begin{array}{l}\text { Strongly } \\
\text { Disagree }\end{array}$ & Total \\
\hline Relationship Management & $\begin{array}{c}61 \\
(19.6 \%)\end{array}$ & $\begin{array}{c}114 \\
(36.5 \%)\end{array}$ & $\begin{array}{c}81 \\
(26.9 \%)\end{array}$ & $\begin{array}{c}53 \\
(17 \%)\end{array}$ & $\begin{array}{l}312 \\
(100 \%\end{array}$ \\
\hline Reciprocity & $\begin{array}{l}21 \\
(6.7 \%)\end{array}$ & $\begin{array}{c}88 \\
(28.2 \%)\end{array}$ & $\begin{array}{c}129 \\
(41.3 \%)\end{array}$ & $\begin{array}{c}74 \\
(23.7 \%)\end{array}$ & $\begin{array}{c}312 \\
(100 \%\end{array}$ \\
\hline $\begin{array}{l}\text { I disclose my personal } \\
\text { information so that my friends } \\
\text { can also disclose theirs }\end{array}$ & $\begin{array}{c}24 \\
(7.7 \%)\end{array}$ & $\begin{array}{c}47 \\
15.1 \%)\end{array}$ & $\begin{array}{c}143 \\
(45.8 \%)\end{array}$ & $\begin{array}{c}98 \\
(32.4 \%)\end{array}$ & $\begin{array}{c}312 \\
(100 \%\end{array}$ \\
\hline Self-Clarification & 44 & 112 & 92 & 64 & 312 \\
& $(14.1 \%)$ & $(35.9 \%)$ & $(29.5 \%)$ & $(20.5 \%)$ & $(100 \%$ \\
\hline Self-Expression & 71 & 117 & 86 & 38 & 312 \\
& $(22.8 \%)$ & $(37.5 \%)$ & $(27.6 \%)$ & $(12.2 \%)$ & $(100 \%$ \\
\hline Social Validation & 33 & 72 & 109 & 98 & 312 \\
& $(10.6 \%)$ & $(23.1 \%)$ & $(34.9 \%)$ & $(31.4 \%)$ & $(100 \%$ \\
\hline I disclose in order to show off & 25 & 42 & 105 & 140 & 312 \\
& $(8 \%)$ & $(13.5 \%)$ & $(33.7 \%)$ & $(44.9 \%)$ & $(100 \%$ \\
\hline
\end{tabular}

As regards the motivational factors for self-disclosure on Facebook and Instagram, barely more than average respondents (56.1\%) agreed that relationship management influenced them, while most respondents $(60.3 \%)$ also agreed that the need for selfexpression affected their action. However, majority of the respondents disagreed that reciprocity $(65.0 \%)$, mutual self-disclosure $(78.2 \%)$, social validation (66.3\%) and the need to show off (78.6\%) influenced their self-disclosure on Facebook and Instagram. Yet, the respondents could not agree or disagree that self-clarification was responsible for their self-disclosure on these social media platforms. These findings on respondents' motivational factors for self-disclosure are further supported by FGD data. For instance, a discussant agreed that 'Many people use Facebook as a platform to express their grievances especially on political matters.' This reveals that Facebook and Instagram users can disclose their personal information because it gives them an opportunity to express their feelings, opinions, emotions and thought.

This finding aligns with the position of Lee et al. (2008), Yang and Tan (2012); Asemah, Okpanachi and Edegor (2013); Rime (2016). Moreover, Yang and Tan (2012), citing Cozby 1973 and Jourard (1959), explain that through self-expression, or emotion relief, people enjoy psychological well-being (e.g., mental health) and experience pleasant inner states. They add that, since the act of self-disclosure itself is such a good and effective way to fulfil self-expression need, people's 
self-disclosure acts will be easily initiated by the need of selfexpression. In addition, it can be further implied that self-expression conforms to the exploratory stage of the social penetration theory where individuals reveal themselves, expressing personal attitudes about different public topics. In addition, it is revealed in the findings that social media users do not disclose in order to have sense of belonging and to seek for liking and social acceptance from others. However, one of the FGD discussants had a contrary view that:

Social media users reveal their personal information online in order to seek for social validation. Some social media users depend on peoples' comments on their post to know whether they are beautiful or handsome. There was case where someone jokingly commented on a picture that the owner of the picture is not fine; the person burst into tears because of the comment. In short, some social media users just depend on the reactions and comment of other people to let them know their social worth and level.

Another discussant also revealed that people could disclose their personal information on Facebook and Instagram in order to get more "likes" on their pictures, videos or stories. Some social media users feel sad if they do not get up to 50 likes on their post. People know that some people might take advantage of what they disclose on social media, but they just want people to notice them, they might probably want to oppress other social media users. It is evident that some social media users derive pleasure; satisfaction and happiness in seeing people comment or like their post. As a matter of fact, a female discussant expressed that 'I feel happy and accepted whenever I get many 'likes' on my pictures; and through that, I am always motivated to post more information online.' This literally means that Facebook and Instagram are platforms where some people get social approval. Thus, it could be reasoned that the feeling of social disapproval could lead some social media users to commit suicide probably after being bullied online. Although, questionnaire respondents and Focus Group discussants had different views as regards social validation, it is a motivating factor for self-disclosure on Facebook and Instagram.

Furthermore, respondents disagreed that the reason they disclose their private information on social media is to show off their achievement and popularity on social media. This finding faults the position of Lee et al. (2008) that some individuals self-disclose out of a need to display their popularity, ability, and so on. Still, while this 
male discussant's submission negates initial findings, it corroborates Lee et al.'s that:

\begin{abstract}
Many social media users in Nigeria always post personal information online in order to update people about their current accomplishment. They just want people to know that they have achieved some things. They want to show off to people that they have attained certain status in life. You can travel from Lagos to London without anybody knowing. Let me just say in Nigeria, people just want to show off on social media. I am this, you are not, you are this, and I am not. And at times, I think it is because they do not know how to use social media.
\end{abstract}

Although a majority of the respondents disagreed, based on the general findings, showing off is a factor that motivates some people to self-disclose their personal information on Facebook and Instagram. Moreover, during FGD sessions, some of the discussants were of the opinions that self-disclosure on online platform could also be motivated by factors that are different from those that have been mentioned earlier in this discussion. Particularly, one noted that: people could disclose their personal information on social media in order to gain sympathy or to receive assistance from people. Social media can also save the lives of people. There was a case of a guy that failed his WAEC woefully. He uploaded his result online and people were sympathising with him. May be he was trying to commit suicide before, but seeing that people have sympathised with him online, he might be motivated to try again and attempt another exam. Another discussant also disclosed that:

One of the main reasons people disclose their personal information on online platforms is to compete with others. And like we have said, many social media users post things online because they become joyful when they get many likes on their post. Some social media users always feel sad whenever people don't like their post. We have heard of cases where people beg other social media users to like their post. There was this incidence that happened on Facebook, a lady used our local Ankara to sew bikini and 
she posted it on social media. People gave many positive comments on her picture. I am sure someone like that will be motivated next time to even go further to post another picture. Meanwhile, people are very deceptive on social media, some people might give a positive comment on your picture but in real life, they don't like you and you will not know. That is just the reality of life.

This means that people could self-disclose their personal information on social media in order to have a sense of belonging and flow with the tempo of the social world. This point confirms the hypothesis of Lee et al. (2008) that the motivation to keep up with trends will have a positive influence on voluntary self-disclosure. They further stressed that a fear that one is out-of-date or behind the times if one does not post certain kind of information can prompt a person to start posting stuffs online. They, therefore, advanced that voluntary self-disclosure stemming from this motivation makes the discloser feel that he or she has something in common with other people. Furthermore, a female Focus Group discussant indicated that:

\begin{abstract}
Social media users can disclose on Facebook and Instagram in order to raise danger alarm. We should also not forget the fact that some people are just trying to reach out. For example, someone whose husband is beating and battering her at home can snap her battered face and post it online in order to seek for help because the husband wants to kill her; I think this kind of disclosure is good. Some people who have been sexually abused or who have experienced domestic violence before could come out on social media and use their personal experience to educate and advise others.
\end{abstract}

This finding validates the submission of Lee et al. (2008), Yang and Tan (2012) and Rime (2016) that one of the main reasons why people disclose on social media is to establish and manage relationship with others. In another viewpoint, Yang and Tan (2012) state that people disclose their information to achieve trust and understanding from others. Therefore, with increased trust and shared understanding, the relationships are more likely to become closer, depending on the 
different relationship phases and personalities. Here, Social Penetration Theory comes to the fore. LittleJohn and Foss (2009) explain that Social penetration theory links self-disclosure to relational interaction by relying on self-disclosure as a primary mechanism for creating varying degrees of intimacy within relationships. They argue further that, self-disclosure is particularly important at the initial stages of a relationship as partners search for similarities and compatibilities. The finding about reciprocity as not a motivation for self-disclosure also negates the previous hypothesis of Barak and Gluck-Ofri (2007) and Lee et al. (2008). These authors submit that people disclose their personal information in order to reciprocate previous disclosure by another person. Notably, Lee et al. (2008) submitted that disclosure seems to beget disclosure, so that people who receive disclosures feel obligated to respond with a personal disclosure of equal intimacy because of the desire to maintain equity.

The implication of the findings can be simply presented thus: respondents do not see self-disclosure on Facebook and Instagram as a mutual benefit; they do not base their self-disclosure on the need to reciprocate. For that reason, their disclosure on Facebook and Instagram might be based on different gratifying factors. Similar to the previous findings, the respondents were also asked if they disclose their private information on social media so that their online friends can also disclose their own; this hypothesis could be regarded as a reversed norm of reciprocity. In light of this, it was found out that social media users do not disclose their personal information in order to prompt their online friends to reciprocate. This suggests that for students in the higher institutions of learning in Ibadan metropolis, reciprocity is not a strong motivational factor for peoples' self-disclosure on social media.

Table 3: The gratifications that respondents derive from selfdisclosure on Social Media

\begin{tabular}{|l|c|c|c|c|c|}
\hline $\begin{array}{l}\text { Gratifications Derived from } \\
\text { Self-disclosure }\end{array}$ & $\begin{array}{l}\text { Strongly } \\
\text { Agree }\end{array}$ & Agree & $\begin{array}{l}\text { Strongly } \\
\text { Disagree }\end{array}$ & Disagree & Total \\
\hline To acquire more friends & $\begin{array}{c}47 \\
(15.1 \%)\end{array}$ & $\begin{array}{c}85 \\
(27.2 \%)\end{array}$ & $\begin{array}{c}112 \\
(35.9 \%)\end{array}$ & $\begin{array}{c}68 \\
(21.8 \%)\end{array}$ & $\begin{array}{c}312 \\
(100 \%)\end{array}$ \\
\hline $\begin{array}{l}\text { To know people more } \\
\text { intimately }\end{array}$ & $\begin{array}{c}45 \\
(14.4 \%)\end{array}$ & $\begin{array}{c}130 \\
(41.7 \%)\end{array}$ & $\begin{array}{c}79 \\
(25.3 \%)\end{array}$ & $\begin{array}{c}58 \\
(18.6 \%)\end{array}$ & $\begin{array}{c}312 \\
(100 \%)\end{array}$ \\
\hline $\begin{array}{l}\text { To kill boredom and pass } \\
\text { time }\end{array}$ & $\begin{array}{c}49 \\
(15.7 \%)\end{array}$ & $\begin{array}{c}124 \\
(39.7 \%)\end{array}$ & $\begin{array}{c}83 \\
(26.6 \%)\end{array}$ & $\begin{array}{c}56 \\
(17.9 \%)\end{array}$ & $\begin{array}{c}312 \\
(100 \%)\end{array}$ \\
\hline $\begin{array}{l}\text { To get peoples' opinion on } \\
\text { issues }\end{array}$ & 63 & 147 & 56 & 46 & 312 \\
& $(20.2 \%)$ & $(47.1 \%)$ & $(17.9 \%)$ & $(14.7 \%)$ & $(100 \%)$ \\
\hline $\begin{array}{l}\text { To sustain online } \\
\text { conversation and maintain } \\
\text { relationship }\end{array}$ & \begin{tabular}{c}
$(16.3 \%)$ \\
\hline
\end{tabular} & $\begin{array}{c}(41.7 \%) \\
(22.1 \%)\end{array}$ & $\begin{array}{c}62 \\
(19.9 \%)\end{array}$ & $\begin{array}{c}312 \\
(100 \%)\end{array}$ \\
\hline
\end{tabular}


Table 2 shows that most respondents 180(57.7\%) disagreed that acquiring more friends informs the gratification they derived from selfdisclosure. However, most respondents agreed that knowing people more intimately $175(56.1 \%)$, killing boredom and passing time 173 (55.4\%), getting peoples' opinion on issues $210(67.3 \%)$ and sustaining and maintaining online conversation $181(58.0 \%)$ constituted gratifications they derived from self-disclosure.Reacting to this view, one of the Focus Group discussants noted that gratifications from social media are personal. The discussant stated that some people make use of Facebook and Instagram mainly for religious purposes. According to this discussant, the type of disclosure that such person will make will be tailored to achieving his religious goals. This finding substantiates the position of Lee et al. (2008) that self-disclosure can sometimes bring personal pleasure. They stressed further that people with this motivation enjoy voluntary self-disclosure, and think of voluntary self-disclosure as an enjoyable play instrument. This also goes in line with the position of Fasae and Adegbilero-Iwari (2016) that students make use of social media to remain up-to-date with trending events and to occupy free time when they are bored.

Findings reveal that most social media users disclose their personal information on social media so that they can get peoples' opinion on issues. This denotes that people who do not have enough psychological and emotional capacity to reason out things by themselves can make use of social media to get peoples' opinions and views on issues. This corroborates the submission of Lee et al. (2008) that some individuals are motivated by a psychological need to share their personal information or knowledge with other people. They emphasize that the self-disclosure with this motivation usually involves a specialized topic in which one may need peoples' view and opinion. Thus, it can be established that Facebook and Instagram have become a platform where people get advice and probably, solutions to issues of life. However, the question worth raising here is 'to what extent can social media be effective in getting peoples' opinion on issues?' For instance, a female FGD discussant in the FGD noted that 'Instead of social media users to express their views on issues, they may engage in cyber bullying and this could complicate an issue instead of resolving it'.

Also, findings presented reveal that most social media users selfdisclose on Facebook and Instagram in order to sustain online conversation and manage relationships with others. This finding conforms to the orientation stage of the Social Penetration Theory. This is the first stage where people get acquainted to one another and the process of interpersonal intimacy development begins (Yang and Tan, 2012). Thus, this is a further confirmation that relationship 
management is one gratification people seek in using social media. On the other hand, a male FGD discussant denied sustenance of online conversation and relationship management as the gratification he derived from self-disclosure thus, 'some social media users disclose personal information just to satisfy their information curiosity as an information source'. He added that these people do not have many friends on their contact list because they are extremely selective.

Some discussants revealed some other gratifications for selfdisclosure on social media. They submitted that social media users might disclose their personal information for social interaction, to get job opportunities, and to confirm information. This point could also be linked to the exploratory-affective stage of the Social Penetration Theory. At this stage, individuals start to reveal themselves, expressing personal attitudes about public topics such as government and education. Furthermore, all actions at this stage are channeled at the development of a close relationship, which is the main essence of self-disclosure (Collins \& Miller, 1994).

Notably, a FGD discussant added that some social media users derive gratification from self-disclosure when what they disclose educates other social media users. From another perspective, a female discussant noted that self-disclosure could be gratifying when it is done in order to clear misconceptions. To lend credence to her position, she gave an example of the issue of Tiwa Salvage and Teebilz. She said that the reason Tiwa Salvage came to the social media to disclose all her personal information is to clear all the misconceptions that her estranged husband's social media outburst had caused. From the aforesaid, it is clear that social media users derive pleasures from disclosing personal information on social media platforms. Prominently, findings show that online self-disclosure helps social media users to pass time, get rid of boredom and get people's opinion on issues. Thus, the more individuals get gratified through self-disclosure online, the more they disclose.

\section{Conclusion and Recommendations}

This study has established the fact that social media users tend to disclose some of their personal information online due to some factors. The findings of this study also support the fact that there are some gratifications that encourage Facebook and Instagram users to disclose their private information online. It, however, concludes that Facebook and Instagram users will continue to disclose their personal information on Facebook and Instagram if the perceived gratification outweighs the privacy risks attached. As long as people still make use of Facebook and Instagram, they will always be motivated by some 
factors that will prompt them to making decisions to disclose personal information online; thus, effective management of privacy on wide platforms such as Facebook and Instagram remains a challenge. Therefore, based on the findings and the conclusion reached; irrespective of the gratifications derived from self-disclosure on Facebook and Instagram, social media users should be careful of the kind of information they post online about themselves. They should exhibit online self-consciousness and self-monitoring so that their privacy can be ensured to a great extent. Individuals should also let their privacy concerns spur them to creating personal privacy boundaries on social media platforms. As well, individuals should cultivate the habit of making use of the privacy control settings that are provided by Facebook and Instagram. Social media users should be orientated on social media use so as to increase their online literacy. With this, they will make use of every social media platform effectively without risking their privacy. As this present study shows, it is pertinent for social media users to be mindful of their environmental and social cultural contexts. This to a considerable extent, could guide individuals' online behaviour.

\section{References}

Ahn, J. (2011). The effect of social network sites on adolescents' social academic development: Current Theories and controversies. Journal of American Society of Information Science, 62(8), 1435-1445.

Ali, A., Srinvas, R.M., \& Ahmad, S. (2016). Needs and motives of Instagram users that predict self-disclosure use: A Case study of young adults in Kuwait. Journal of Creative Communications, 11(2), 88-101.

Asemah, E. S., Okpanachi, R.A., Edegor, L.O.N. (2013). Influence of social media on the academic performance of the undergraduate students of Kogi State University, Ayingba, Nigeria. Research on Humanities and Social Sciences, 3(12), 90-97.

Barak, A. \& Gluck-Ofri, O. (2007). Degree and reciprocity of selfdisclosure in online forums. Journal of Cyber Psychology and Behaviour, 10(3), 407-417.

Baruah, T. D. (2012). Effectiveness of social media as a means of communication and its potential for technology enabled connection: A micro-level study. International Journal of Scientific and Research Publication, 2(5), 1-10.

Bazarova, N. N. \& Choi, Y. H. (2014). Self-disclosure in social media: Extending the functional approach to disclosure motivations 
and characteristics on social network sites. Journal of Communication, 64(4), 635-657.

Boyd, D. M. \& Ellison, N. P. (2008). Social network sites: Definition, history and scholarship. Journal of Computer Mediated Communication, 13, 210-230.

Chapman, A. (2003). Johari window: A model for self-awareness personal development, group development and understanding relationship. Retrieved 25 May 2017, from www.businessballs.com.

Debatin, B., Lovejoy, J. P., Horn, A., \& Hughes, B. N. (2009). Facebook and online privacy: Attitudes, behaviours, and unintended consequences. Journal of Computer Mediated Communication, 15, 83-108.

Eke, H.N., Omekwu, C.O \& Odoh, J. N. (2014). The use of social netwoking sites among the undergraduate students of University of Nigeria, Nsukka. Library Philosophy and Practice (e-journal) Paper 1195.

Fasae, J. K. \& Adegbilero-Iwari, I. (2016). Use of social media by science students in public universities in southwest Nigeria. The Electronic Library, 34(2), 213-222.

Ghamari, N. \& Mellbin, N. (2015). Disclosing personal information to social network sites providers: The role of trust, risk and personal benefit. Master's dissertation, Uppsala University, Norway.

Hu, Y., Manikonda, L., \& Kambhampati, S. (2014). What we Instagram: A first analysis of Instagram photo content and user types. Tempe, AZ: Department of Computer Science, Arizona State University.

Harvey, J. \& Soltren, J. H. (2005). Facebook: Threats to privacy. Retrieved 23 May 2017, from www.groups.csail.mit.edu.

Kusyanti, A. \& Safitiri, O. (2016). "How do I look": Self-disclosure of Instagram users in Indonesia. Journal of Education and Social Sciences, 5(2), 242-247.

Ledbetter, A. M. et al. (2010). Attitudes toward online social connection and self-disclosure as predictor on Facebook communication and relationship closeness. Texas: Sage Publication.

Lee, D. H., Im, S. \& Taylor, C. R. (2008). Voluntary self-disclosure of information on the Internet: A multi-method study of the motivations and consequences of disclosing information on blogs. Journal of Psychology and Marketing, 25(7), 692-710.

Lin, H., Tov, W. \& Qui, L. (2014). Emotional disclosure on social networking site: The role of network structure and psychological needs. Journal of Computer in Human Behaviour, 4, 342-350. 
LittleJohn, S. \& Foss, K. (2008). Theories of communication (9 ${ }^{\text {th }}$ edition). Belmont: Thomson Wardsworth.

LittleJohn, S. W. \& Foss, K. (2009). Encyclopedia of communication theory. New York: Sage Publication.

Madden, M. et al. (2013). Teens, social media and privacy. Pew Research Center, 21, 2-86 Bertman Center for Internet and Society at Harvard University.

Masaviru, M. (2016). Self-disclosure: Theories and model reviews. Journal of Culture and Development, 18, 43-47.

McAllister, H. A. (1980). Self-disclosure and liking: Effects for senders and receivers. Journal of Personality and Social Psychology, 48(4), 409- 418.

Omoera, O.S., Aiwuyo, O.M., Edemode, J.O. \& Anyanwu, B.O. (2018). Impact of social media on the English language writing abilities of undergraduates in Ekpoma, Nigeria. GiST: Education and Learning Research Journal, 17, 59-80.

Rime, B, (2016).Self-disclosure. Encyclopedia of mental health ( $2^{\text {nd }}$ edition). Volume 4. Waltham MA: Academic Press. 66-74.

Sprecher, S. \& Hendrick, S. S. (2004).Self-disclosure in intimate relationships: associations with individual and relationship characteristics over time. Journal of Social and Clinical Psychology, 23, 857-877.

Steinberg, S. (2007). An introduction to communication studies. Cape Town: A Publication of Juta and Co Ltd.

West, R. \& Turner, L.H. (2010). Introducing communication theory: Analysis and application. Boston: McGraw-Hill.

Yang, L., \& Tan, B. C. (2012). Self-disclosure on online social networks. Motives, context features and media capabilities. A Publication from the Thirty Third International Conference of Information Systems, Orlando.

Yat, S. C. (2012). Factors affecting online self-disclosure of university Facebook users. BB degree project, Hong Kong Baptist University, Hong Kong. 